\title{
KEPATUHAN PAJAK, NORMA SOSIAL MASYARAKAT , PENEGAKAN HUKUM, DAN MORAL PAJAK PERUSAHAAN AGRO PADA BURSA EFEK DI INDONESIA
}

\author{
Yustina Peniyanti Jap \\ Jurusan Akumtansi, Fakultas Ekonomi, Universitas Tarumanagara, Jakarta \\ yustina.peniyanti@gmail.com
}

\begin{abstract}
Indonesian annual tax receipts in the government budgets mostlywere reached below 100\%, indicating that the Economic growth based on the fiscal policies applied is not followed by tax payments by the Indonesians. It indicates that not all of the tax payers complies their payment according to the tax due from the regulations.

The purpose of the study is to examine and analyze the effect of taxpayers'social norm, law enforcement, and taxpayers 'moral to the taxpayers' compliance in agro public companies listed on the Indonesia Stock Exchange. Using questionnaires to the tax managers and or supervisors from 14 Agro companies as respondents, we describe and analyzedthe data by multiple regression in order to examine whether taxpayers 'social norm, law enforcement, and taxpayers'moral affect the taxpayers' compliance. The result foundtaxpayers'social norms, law enforcement and taxpayers' moral simultaneously have a positive and significant effected on taxpayers' compliance on paying taxes, but only taxpayers' social norm impact the tax complance. Government can not rely on law emforcement (inspections and fines)and taxpayers' moral, but especially on taxpayers' social norms in order to make the taxpayers comply to pay tax. These are reflection of public perception of the administration of taxation and government.
\end{abstract}

Keywords: tax compliance, social norm, law enforcement, taxpayers moral.

\section{PENDAHULUAN}

Penerimaan pajak pada Anggaran Pendapatan Belanja Negara (APBN) di Indonesiakebanyakan belum sesuai dengan rencana (pencapaian masih dibawah $100 \%$ rencana).Disamping itu pertumbuhan APBN tidak diikuti pertumbuhan penerimaan pajak.Hal ini menunjukkan adanya pengeluaran pemerintah yang tidak diikuti penerimaan pajak yang sesuai.Walaupun pada kenyataannya rencana penerimaan pajak terus mengalami peningkatan, namun penerimaan pajak tersebut belum sesuai dengan pertumbuhan ekonomi.Pada tahun 2012 - 2017 penerimaan pajak bertumbuh dari 980 triliun, menjadi 1077 triliun, 1147 triliun, 1241 triliun, 1539 triliun dan menurun menjadi 1499 triliun. Hal ini menggambarkan bahwa pertumbuhan ekonomi berdasarkan kebijakan fiskal yang diterapkan Pemerintah Indonesia tidak diikuti oleh pembayaran pajak oleh masyarakat Indonesia yang optimal.

Tabel 1.Penerimaan Perpajakan tahun 2012-2017

\begin{tabular}{lllrrrr} 
Penerimaan & \multicolumn{1}{l}{2012} & 2013 & 2014 & \multicolumn{1}{c}{2015} & \multicolumn{1}{l}{2016} & 2017 \\
Perpajakan & $980.518,1$ & 1.077 .306$, & $1.146 .865,8$ & $1.240 .418,9$ & $1.539 .166,2$ & $1.498 .871,6$ \\
Dalam Negeri & $930.861,8$ & $1.029 .850,1$ & $1.103 .217,6$ & $1.205 .478,9$ & $1.503 .294,7$ & $1.464 .796,5$ \\
Perdagangan Int'l & $49.656,3$ & $47.456,6$ & $43.648,1$ & $34.940,0$ & $35.871,5$ & $34.075,1$
\end{tabular}

Sumber: Nota Keuangan 2017

Tingkat pertumbuhan penerimaan negara bukan pajak meningkat rata-rata $11 \%$ setiap tahun, hal ini guna menyeimbangi pengeluaran pemerintah yang tidak diikuti penerimaan pajak yang seimbang dengan pengeluaran pemerintahnya. Pengeluaran pemerintah tidak diikuti dengan penerimaan pajak yang seimbang. Berikutnya permasalahan ini dapat dilihat pada gambaran penerimaan pajak di Indonesia bila dibandingkan dengan negara - negara lain, penerimaan pajak di Indonesia masih belum optimal. Tax ratio atau rasio penerimaan pajak terhadap Produk Domestik Bruto (PDB) di Indonesia menunjukan peningkatan, dapat diartikan keberhasilan dalam proses pemungutan pajak. Namun dalam pelaksanaan peningkatan tax ratio di Indonesia ternyata masih dibawah negara-negara tetangga.Tax ratiodi Indonesia masih 11,0 -12,3 persen (tahun 2009-2012) diluar penerimaan pajak daerah dan Sumber Daya Alam (SDA) migas, bila termasuk 
penerimaan pajak daerah dan SDA, tax ratio Indonesia sebesar 14,1 persen-15,8 persen. Jika dibandingkan dengan negara-negara ASEAN pada tahun yang sama seperti Brunei 44\%; Malaysia 22.4\%; Singapore

15.9\%; Thailand 20\%; dan Philippine 14.7\%, makatax ratio Indonesia seimbang dengan Singapore, lebih tinggi dari Philippines tetapi lebih rendah dari Thailand, Malaysia dan Brunei. (The World Fact Book, 2013). Kendala utama nya yaitu kepatuhan Wajib Pajak (tax compliance) yang masih dapat dan perlu ditingkatkan.. Data-data tersebut diduga merupakan gambaran adanya masalah dalam kepatuhan pajak di Indonesia.

Berdasarkan uraian tersebut tampak bahwa ternyata kepatuhan pajak di Indonesia belum memadai dan masih perlu ditingkatkan.Hal ini menunjukkan bahwa walau telah dilakukan upaya-upaya agar wajib pajak patuh membayar pajak, kepatuhan wajib pajak ternyata masih perlu ditingkatkan..

Penerimaan pajak tertinggi masih didominasi oleh Pajak Penghasilan (PPh), kemudian disusul oleh Pajak Pertambahan Nilai (PPN) dan Bea Cukai, berkaitan dengan hal ini secara makro perusahaanlah yang membayar pajak kepada negara, tetapi secara mikro perusahaan hanyalah semacam perantara dalam pembayaran pajak. Pada kenyataannya jumlah pajak yang dibayar ke negara tersebut menjadi beban berbagai pihak yang berkepentingan, seperti pemegang saham, konsumen, karyawan atau kombinasi ketiganya.

Pada dasarnya baik wajib pajak maupun otoritas pajak menghendaki tingkat kepatuhan yang tinggi terhadap semua ketentuan perpajakan. Tetapi hal ini seringkali terkendala dengan persepsi wajib pajak terhadap manfaat yang dapat diperoleh melalui pembayaran pajak. Kepatuhan membayar pajak dilihat dari tingkat kepatuhan pelaporan SPT tahun 2008-2010 masih 60\% (Tabel 2)

\section{Tabel 2}

Tingkat Kepatuhan Pelaporan SPT Tahun 2008-2010

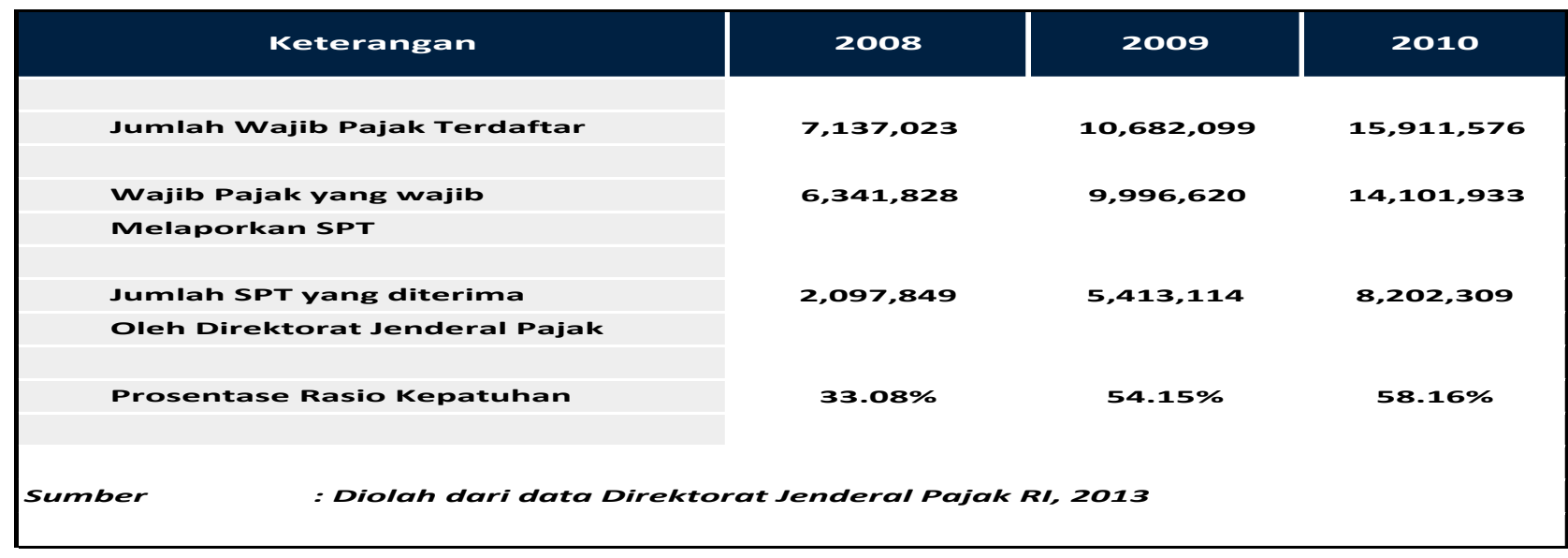

Catatan literatur berikut adalah variabel-variabel yang berkaitan dengan kepatuhan pajak. Sikap dan kendali perilaku mempengaruhi niat untuk patuh, sementara norma subjektif dan kebijakan sunset policy tidak mempengaruhi niat untuk patuh. Salah satu variabel bebas norma subyektif ternyata tidak berpengaruh pada perilaku kepatuhan membayar pajak (Ernawati dan Purnomosidhi, 2011). Lain lagi dengan jumlah account representative dan jumlah pemeriksaan sebagai penjabaran penegakan hukum secara signifikan mempengaruhi kepatuhan wajib pajak( Riyanto, 2012).Catatan tentang moral pajak di Indonesia masih karena adanya paksaan faktor ekstemal berupa besarnya denda pajak dibanding karena motivasi intrinsik individu (Cahyonowati, 2011), sehingga efektivitas kinerja pemungutan pajak yang diukur dengan tax ratiomasih pada ratio $13 \%$ - 16\%. Pada prinsipnya tax ratiodipengaruhi oleh dua hal. Pertama, kepatuhan Wajib Pajak untuk melakukan pembayaran pajak. Kepatuhan pajak dipengaruhi oleh beberapa faktor lainnya seperti: adanya kesadaran dalam membayar pajak yang tumbuh sebagai suatu budaya dalam suatu komunitas, adanya manfaat yang dapat dirasakan (baik secara langsung maupun tidak langsung) dari 
pembayaran pajak, pelayanan oleh Kantor Pajak Daerah serta law enforcement. Kedua, penggalian potensi pajak. Penggalian potensi pajak dilakukan melalui kegiatan intensifikasi pajak dan ekstensifikasi pajak. Disimpulkan bahwa terdapat hubungan yang signifikan antara efektifitas pemungutan pajak dengan tax ratio, dengan tingkat hubungan sedang (besarnya nilai koefisien korelasi sebesar 50,2). Tingkat hubungan koefisien korelasi sebesar 50,2 (sedang) menunjukkan bahwa faktor diluar efektifitas pemungutan pajak juga

cukup besar mempengaruhi tax ratio, seperti pembentukan kepatuhan sukarela Wajib Pajak, kepercayaan terhadap sistim perpajakan, serta manfaat yang dapat dinikmati dari pembayaran pajak (Wijito, 2012). Dari latar belakang penelitian masalah kepatuhan pajak diidentifikasi karena sikap dan kendali perilaku WP, norma sosial WP., kebijakan Pajak (Sunset policy, Tax amnesty, dll), jumlah pemeriksaan pajak (tergantung jumlah petugas pajak), pengakan hukum, moral WP, suka rela WP, pengetahuan dan kepercayaan WP terhadap sistim perpajakan serta pembiayaan negara, pelayanan Kantor Pajak (KPP), keadilan pajak, dan manfaat pajak.

Dugaan bahwa kepatuhan pajak sebagian besar dipengaruhi oleh norma social WP., penegakan hukum, dan moral WP.

Pertanyaan penelitian :apakah norma sosial wajib pajak, penegakan hukum, dan moral wajib pajak baik secara bersama-sama maupun secara parsial mempengaruhi kepatuhan membayar pajak. Hal ini dibuktikan dalam penelitian ini melalui pengukuran dimensi masing-masing variabel dengan alat kuesioner diambil dari petugas perpajakan pada perusahaan agro yang tercatat pada Bursa Efek Indonesia.

\section{METODE PENELITIAN}

Metode penelitian yang digunakan adalah deskriptif kuantitatif dengan analisis data menggunakan regresi linier.Data primer diperoleh dari jawaban kuesioner responden. Populasi penelitian seluruh perusahaan terbuka sektor agrobisnis yang terdaftar di Bursa Efek Indonesia.

Dalam penelitian ini obyek penelitian berupa norma sosial wajib pajak, penegakan hukum, moral wajib pajak dan kepatuhan membayar pajak.

\section{Metode Penarikan Sampel}

Populasi perusahaan agro yang terdaftar di BEI adalah $\mathrm{N}=14$ perusahaan, oleh karena jumlah populasi sedikit, maka rumus Slovin tidak digunakan dan penelitian dilakukan dengan sampling jenuh atau seluruh populasi dianggap sampel, sehingga jumlah sampel sama dengan jumlah populasi, $\mathrm{n}=14$ perusahaan .

Pada penelitian ini seluruh populasi dijadikan sampel. Responden penelitian ditentukan dengan mempertimbangkan bahwa responden benar-benar mewakili badan usaha yang terpilih sebagai sampel. Dalam penelitian ini ditetapkan bahwa responden adalah petugas Public Relation atau manager dana tau supervisor yang bertugas menyiapkan administrasi perpajakan perusahaan atau karyawan lain yang ditunjuk oleh perusahaan tersebut untuk mewakili.

\section{Dimensi Variabel}

1) Variabel Kepatuhan Wajib Pajak (Y)

Wajib Pajak Patuh adalah Wajib Pajak yang memenuhi kriteria tertentu (sebagai persyaratandalam pengembalian pendahuluan atas kelebihan pembayaran pajak):

a) Tepat waktu menyampaikan Surat Pemberitahuan Pajak baik Pajak Tahunan maupun Pajak Masa.

b) Tidak mempunyai tunggakan pajak untuk semua jenis pajak, kecuali telah memperoleh izin untuk mengangsur atau menunda pembayaran pajak.

c) Tidak pernah dijatuhi hukuman karena melakukan tindakan pidana dibidang perpajakan dalam jangka waktu 10 tahun terakhir yang mengakibatkan kerugian Negara.

d) Apabila dilakukan pemeriksaan pajak, koreksi fiskal yang dilakukan oleh pemeriksa pajak untuk setiap jenis pajak yang terutang tidak lebih dari $10 \%$ (sepuluh persen) dilihat dari penghasilan bruto (PKP). 
2) Variabel Norma Sosial Wajib Pajak $\left(\mathrm{X}_{1}\right)$

Keyakinan normatif (normative beliefs) yaitu keyakinan tentang harapan normatif orang lain yang memotivasi seesorang untuk memenuhi harapan tersebut (normative beliefs and motivation to comply). Keyakinan normatif merupakan indikator yang kemudian menghasilkan norma subjektif (subjective norms). Jadi norma subjektif adalah persepsi seseorang tentang pengaruh sosial dalam membentuk perilaku tertentu.(Ernawati dan Purnomosidhi, 2011)

3) Variabel Penegakan Hukum $\left(\mathrm{X}_{2}\right)$

Serangkaian kegiatan menghimpun dan mengolah data, keterangan dan atau barang bukti yang dilaksanakan secara obyektif dan professional berdasarkan suatu standar pemeriksaan untuk menguji kepatuhan pemenuhan kewajiban perpajakan dan atau tujuan lain dalam rangka melaksanakan ketentuan peraturan perundang-undangan perpajakan (pasal 1 angka 25 UU KUP). Penegakan hukum dalam penelitian ini meliputi kegiatan pemeriksaan dan pengenaan denda kepada wajib pajak.

\section{4) Variabel Moral Wajib Pajak $\left(\mathrm{X}_{3}\right)$}

Dalam penelitian ini karena yang diteliti adalah badan usaha, maka faktor yang mempengaruhi moral wajib pajak terdiri dari variabel sosial kemasyarakatan yang dipengaruhi oleh dimensi: Kepercayaan terhadap sistem hukum dan system perpajakan; Kebanggaan nasional; Penghindaran pajak persepsian; dan Desentralisasi. (Chayonowati, 2011)

Tabel 2

Operasionalisasi Variabel Penelitian

\begin{tabular}{|c|c|c|}
\hline Variabel & Dimensi & Jumlah Pertanyaan \\
\hline \multirow{3}{*}{ Kepatuhan Wajib Pajak $(\mathrm{Y})$} & Tepat waktu & 2 \\
\cline { 2 - 3 } & Tidak punya tunggakan & 2 \\
\cline { 2 - 3 } & Tidak pernah dijatuhi hukuman & 2 \\
\hline \multirow{2}{*}{ Norma Sosial Wajib Pajak $\left(\mathrm{X}_{1}\right)$} & Keyakinan normatif & 2 \\
\cline { 2 - 3 } & Motivasi & 2 \\
\hline \multirow{2}{*}{ Penegakan Hukum $\left(\mathrm{X}_{2}\right)$} & Pemeriksaan & 2 \\
\cline { 2 - 3 } & Denda & 2 \\
\hline \multirow{3}{*}{ Moral Wajib Pajak $\left(\mathrm{X}_{9}\right)$} & $\begin{array}{c}\text { Kepercayaan terhadap sistem } \\
\text { hukum dan perpajakan }\end{array}$ & 2 \\
\cline { 2 - 3 } & Kebanggaan nasional & 2 \\
\cline { 2 - 3 } & Penghindaran pajak persepsian \\
\cline { 2 - 3 } & Desentralisasi & 2 \\
\hline
\end{tabular}

Sumber: Landasan teori dan peraturan perpajakan

\section{E. Uji hipotesis}

Hipotesis 1,2,3 diuji dengan uji-t, sedangkan hipotesis 4 diuji dengan uji-F. Uji hipotesis dilakukan dengan analisis regresi linier berganda.

Persamaan model penelitian adalah sebagai berikut

$\mathrm{Y}=\mathrm{a}+\mathrm{b} 1 \mathrm{X}_{1}+\mathrm{b} 2 \mathrm{X}_{2}+\mathrm{b} 3 \mathrm{X}_{3}+\varepsilon$

Keterangan :

Y

$b_{1}-b_{3}$

a

$\mathrm{X}_{1}$

$\mathrm{X}_{2}$

$\mathrm{X}_{3}$

$\varepsilon$ $=\quad$ Kepatuhan wajib pajak

$=\quad$ Koefisien regresi masing-masing variabel bebas

$=\quad$ Konstanta

$=\quad$ Norma Sosial wajib pajak

$=\quad$ Penegakan hukum

$=\quad$ Moral wajib pajak

$=\quad$ Estimate of error dari masing-masing variabel 


\section{Koefisien Determinasi (Goodness of Fit)}

Ajusted $\mathrm{R}$ Squaredigunakan untuk pengujian kecocokan model pengaruh variabel Norma Sosial wajib pajak $\left(\mathrm{X}_{1}\right)$, Penegakan hukum $\left(\mathrm{X}_{2}\right)$, dan Moral wajib pajak $\left(\mathrm{X}_{3}\right)$ terhadap Kepatuhan Pajak..

\section{HASIL DAN ANALISIS DATA}

\section{Demografi Responden Subyek Penelitian}

Distribusi usia responden menunjukkan bahwa yang mewakili perusahaan untuk menjawab kuesioner penelitian sebagian besar berusia antara 25-40 tahun (72\%) yang merupakan usia yang produktif dan umumnya sudah mempunyai jabatan yang cukup baik sehingga dipercaya oleh perusahaan untuk mewakili.

Distribusi gender responden tersebut menunjukkan bahwa gender perempuan dan laki-laki mempunyai kemungkinan yang sama untuk dipercaya mewakili perusahaan menjawab pertanyaan-pertanyaan yang ada dalam kuesioner penelitian.

Distribusi jabatan responden tersebut mengindikasikan bahwa pada umumnya sebagian besar perusahaan menunjuk petugas public relation untuk menjawab pertanyaan-pertanyaan dalam kuesioner penelitian. Hal ini wajar, karena petugas public relation adalah petugas yang memang bertanggung jawab untuk berhubungan dengan pihak luar dan memberikan jawaban-jawaban yang dapat mengangkat citra perusahaan.

\section{Analisis dan Pembahasan}

Persamaan regresinya:

$$
\mathrm{Y}=2.419+0.964 \mathrm{X}_{1}+0.160 \mathrm{X}_{2}+0.147 \mathrm{X}_{3}
$$

Keterangan :

$$
\begin{aligned}
& Y=\text { Kepatuhan Wajib Pajak } \\
& X_{1}=\text { Norma Sosial } \\
& X_{2}=\text { Penegakan Hukum } \\
& X_{3}=\text { Moral Wajib Pajak }
\end{aligned}
$$

\begin{tabular}{|c|c|c|c|c|c|c|}
\hline \multirow{2}{*}{\multicolumn{2}{|c|}{ Model }} & \multicolumn{2}{|c|}{ Unstandardized Coefficients } & \multirow{2}{*}{$\begin{array}{c}\begin{array}{c}\text { Standardized } \\
\text { Coefficients }\end{array} \\
\text { Beta }\end{array}$} & \multirow[b]{2}{*}{$\mathrm{t}$} & \multirow[b]{2}{*}{ Sig. } \\
\hline & & $\mathrm{B}$ & Std. Error & & & \\
\hline \multirow[t]{4}{*}{1} & (Constant) & 2.419 & 1.226 & & 1.972 & .077 \\
\hline & NORMA & .964 & .348 & .690 & 2.770 & .020 \\
\hline & HUKUM & .160 & .416 & .111 & .386 & .708 \\
\hline & MORAL & .147 & .231 & .193 & .637 & .539 \\
\hline
\end{tabular}

Tabel 3Coefficients ${ }^{\mathrm{a}}$

a. Dependent Variable: KEPATUHAN

Sumber: Hasil olah jawaban kuesioner dengan SPSS

Hanya hipotesis 1 yang signifikan positif. Norma social WP signifikan positif mempengaruhi kepatuhan pajak WP..

Sementara Penegakan hukum dan moral WP tidak signifikan positif mempengaruhi kepatuhan pajak WP.

Tabel 3 menunjukkan bahwa persamaan regresi liniernya adalah 
$\mathrm{Y}=2.419+0.964 \mathrm{X}_{1}+0.160 \mathrm{X}_{2}+0.147 \mathrm{X}_{3}+1.226$ menunjukan bahwa Kepatuhan Membayar Pajak dipengaruhi secara positif oleh Norma Wajib Pajak, Penegakan Hukum dan Moral Wajib Pajak; jika Norma Wajib Pajak, Penegakan Hukum dan Moral Wajib Pajak meningkat maka Kepatuhan Membayar Pajak juga meningkat; demikian pula sebaliknya.

Hasil Persamaan regresi linier menunjukkan bahwa Norma Wajib Pajak (koefisien 0.964),signifikan dan dominan mempengaruhi kepatuhan pajak WP.

Tabel 4. Model Summary

\begin{tabular}{|l|r|r|r|r|}
\hline Model & $\mathrm{R}$ & $\mathrm{R}$ Square & $\begin{array}{c}\text { Adjusted R } \\
\text { Square }\end{array}$ & $\begin{array}{c}\text { Std. Error of the } \\
\text { Estimate }\end{array}$ \\
\hline 1 & $.989^{\mathrm{a}}$ & .977 & .970 & 1.065 \\
\hline
\end{tabular}

Kecocokan modelNorma Wajib Pajak, Penegakan Hukum, danMoral Wajib Pajak, mempengaruhikepatuhan pajakWP dengan adjusted $\mathrm{R}$ square senilai 0.971 yang mendekati 1; sehingga dapat disimpulkan bahwa hubungan antara Norma Wajib Pajak, Penegakan Hukum dan Moral Wajib Pajak secara simultan dengan Kepatuhan Membayar Pajak adalah kuat (mempunyai Goodness of Fit yang baik).

Tabel 5.ANOVA ${ }^{\mathrm{b}}$

\begin{tabular}{|ll|r|r|r|r|r|}
\hline Model & & Sum of Squares & df & Mean Square & \multicolumn{1}{c|}{$\mathrm{F}$} & Sig. \\
\hline 1 & Regression & 486.375 & 3 & 162.125 & 142.971 & $.000^{\mathrm{a}}$ \\
& Residual & 11.340 & 10 & 1.134 & & \\
& Total & 497.714 & 13 & & & \\
& & & & & \\
\hline
\end{tabular}

a. Predictors: (Constant), MORAL, NORMA, HUKUM

b. Dependent Variable: KEPATUHAN

Tabel 5 menunjukan bahwa model kepatuhan pajak dengan prediktor Norma Wajib Pajak $\left(\mathrm{X}_{1}\right)$, Penegakan Hukum $\left(\mathrm{X}_{2}\right)$ dan Moral Wajib Pajak $\left(\mathrm{X}_{3}\right)$ signifikan atau mempengaruhi kepatuhan pajak Wp.

Kesimpulan bahwa kepatuhan pajak dipengaruhi positif oleh norma social WP, penegakan hukum dan moral pajak WP. Namun bila menggunakan model ini untuk generalisasi seluruh WP maka yang signifikan mempengaruhi positif adalah Norma social WP. Sementara penegakan hukum dan moral pajak WP tidak signifikan positif mempengaruhi kepatruhan pajak.

Implikasinya bahwa hanya norma social yang dapat meningkatkan penerimaan pajak di Indonesia, dengan catatan semua WP mempunyai pendapat seperti WP industri Argo. Jadi hasil penelitian ini mempunyai keterbatasan bahwa WP merupakan WP pada industri Argo. Bila hasil penelitian ini akan digunakan dalam meningkatkan penerimaan pajak di Indonesia, maka responden harus mewakili seluruh responden populasi WP di Indonesia.

\section{Pembahasan}

Sejak tahun 1984 sistem pemungutan pajak di Indonesia menggunakan sistemself assessment; wajib pajak diberi wewenang untuk menentukan sendiri jumlah pajak yang terutang setiap tahunnya sesuai dengan perundang-undangan perpajakan yang ber-laku. Penerapan sistem ini akan efektif apabila kondisi kepatuhan sukarela (voluntary compliance) pada masyarakat telah terbentuk. Kepatuhan sebagai fondasi self assessmentdapat dicapai apabila elemen-elemen kunci seperti program pelayanan yang baik kepada wajib pajak; prosedur yang sederhana dan memudahkan wajib pajak; program pemantauan kepatuhan dan verifikasi yang efektif; dan pemantapan law enforcement secara tegas dan adil telah diterapkan secara efektif.

\section{Norma Sosial mempengaruhi kepatuhan membayar pajak}


Ernawati dan Purnomosidhi (2011) menemukan Norma subjektif adalah keyakinan wajib pajak tentang kekuatan pengaruh orang-orang atau faktor lain di lingkungannya yang memotivasi seseorang untuk melakukan kepatuhan pajak atau tidak melakukan kepatuhan pajak. Sikap terhadap kepatuhan pajak yang positif atau norma sosial yang sudah terbentuk dari pengetahuan dan pengalaman wajib pajak maupun

pengalaman orang atau badan lain akan membentuk niat wajib pajak untuk patuh atau tidak patuh. Namun, niat ini berubah karena pengaruh orang atau badan disekitarnya atau faktor-faktor lainnya.

Dalam penelitian ini norma sosial dari norma wajib pajak yang digunakan adalah keyakinan masyarakat dan motivasi untuk mematuhinya. Hasil analisis penelitian menunjukkan bahwa secara parsial norma sosial mempunyai pengaruh positif yang signifikan terhadap kepatuhan membayar pajak; ini berarti hasil penelitian ini sejalan dengan hasil penelitian Ernawati dan Purnomosidhi (2011).

\section{Penegakan Hukum mempengaruhi kepatuhan membayar pajak}

Hukum pajak memuat pula unsur-unsur hukum tata Negara dan hukum pidana (Resmi, 2008) agar WP patuh pajak.

Cahyonowati (2011) menyatakan bahwa hukum ekonomi telah banyak digunakan dalam penelitian terdahulu mengenai kepatuhan pajak. Motivasi wajib pajak untuk taat pajak atau menggelapkan pajak

dianalisis dengan berdasarkan motivasi ekonomi dari wajib pajak. Pendekatan tradisional ini berguna untuk menganalisis motif ekonomi dibalik kejahatan termasuk juga kejahatan dalam perpajakan. Torgler (2002) menemukan bahwa pemeriksaan pajak (tax audit) berhubungan positif dengan tingginya tax morale. Hal ini karena wajib pajak yang patuh akan melihat bahwa mekanisme hukum yang dibangun oleh fiskus mampu menghukum wajib pajak yang tidak taat. Sebaliknya, denda pajak yang tinggi akan menurunkan motivasi individu untuk membayar pajak.

Riyanto (2012) menyatakan bahwa pemeriksaan pajak adalah serangkaian kegiatan menghimpun dan mengolah data, keterangan dan atau barang bukti yang dilaksanakan secara obyektif dan professional berdasarkan suatu standar pemeriksaan untuk menguji kepatuhan pemenuhan kewajiban perpajakan dan atau tujuan lain dalam rangka melaksanakan ketentuan peraturan perundang-undangan perpajakan (pasal 1 angka 25 UU KUP). Jadi tujuan pemeriksaan adalah pertama untuk menguji kepatuhan pemenuhan kewajiban perpajakan dan yang kedua adalah untuk tujuan lain.

Penegakan hukum dalam penelitian ini meliputi kegiatan pemeriksaan dan pengenaan denda kepada wajib pajak. Ternyata pemeriksaan pajak yang tujuan nya agar patuh pajak tidak signifikan membuat WP patuh pajak.

\section{Moral wajib pajak mempengaruhi kepatuhan membayar pajak}

Kepatuhan wajib pajak badan dipengaruhi oleh norma subjektif, pengendalian perilaku pegawai bagian pajak, niat pegawai bagian pajak untuk patuh pajak, iklim di dalam organisasi dan kondisi keuangan perusahaan (Kiswara, 2009). Namun agar warga negara mematuhi norma hukum yang ada sepanjang mereka percaya bahwa warga negara yang lain juga patuh. Ketidakpatuhan seseorang juga akan mempengaruhi ketidakpatuhan individu lainnya karena persepsi mengenai ketidakpatuhan akan menimbulkan perilaku oportunistik. Tindakan penggelapan pajak (tax evasion) yang dilakukan individu akan merusak tax morale individu lainnya (Cahyonowati, 2011).

Moral pajak menjadi salah satu penentu utama kepatuhan pajak. Literatur yang membahas hubungan antara moral pajak dan perilaku kepatuhan secara konsisten melaporkan adanya korelasi positif dari dua elemen tersebut. Umumnya, negara-negara dengan tingkat moral pajak tinggi mempunyai tingkat kepatuhan pajak yang tinggi dan kepalsuan perekonomian (shadow economy) yang rendah (Nichita dan Bătrâncea, 2012).Namun hasil penelitian menemukan bahwa moral pajak tidak signifikan mempengaruhi kepatuhan pajak.

\section{DAFTAR PUSTAKA}

Ajzen, I. (1991). The Theory Planned Behavior. Organizational Behavior and Human Decision Processes. 50: $179-211$.

Algifari. (2000). Analisis Regresi, Teori, Kasus \& Solusi. Yogyakarta: BPFE UGM. 
Alm, James \& McClelland, Gary H \& Schulze, William D. (1999). Changing the Social Norm of Tax Compliance by Voting. Copyright 1999 by WWZ and Helbing \& Lichtenhahn Verlag AG

Ardian, Zul Afdi dan Barata, Atep Adya. (1989). Perpajakan Jilid I. Bandung: Armico.

Arniati. (2009). Peran Theory of Planned Behavior terhadap Ketaatan Wajib Pajak. Seminar Nasional Perpajakan II. Universitas Trunojoyo. Madura.

Blanthorne, C. M. 2000. The Role of Opportunity and Beliefs On Tax Evasion: A Struc-tural Equation Analysis. Dissertation. Arizona State University.

Cahyonowati, Nur. (2011). Model Moral dan Kepatuhan Perpajakan: Wajib Pajak Orang Pribadi. JAAI Volume 15 No. 2, Desember 2011: 161-177

Cahyonowati, N. (2008). Taxation in Indonesia and environmental costing: How much tax payers pay for natural resource exploration? Makalah dipresentasikan dalam Global Conference on Environmental Taxation ke-9 di Singapura pada 6-7 November 2008.

Cullis, John \& Jones, Philip \& Savoia, Antonio. (2012). Social norms and tax compliance: Framing the decision to pay tax.

Darmayanti, T. W. (2004). Pelaksanaan Self Assesment System Menurut Wajib Pajak (Studi Kasus Pada Wajib Pajak Badan Salatiga). Jurnal Ekonomi dan Bisnis. X (1): 109-128

Edlund dan Aberg. (2002). Social Norms and Tax Compliance. Swedish Economic Policy Review 9 (2002) 201-228

Edoardo Di Porto. (2009). Audit, tax compliance and undeclared work: an empirical analysis.

Ernawati, Widi Dwi dan Purnomosidhi, Bambang. (2011). Pengaruh Sikap, Norma Subjektif, Kontrol Perilaku yang Dipersepsikan, dan Sunset Policy terhadap Kepatuhan Wajib Pajak dengan Niat sebagai Variabel Intervening. Politeknik Negeri Malang, Universitas Brawijaya.

Grasmick, H. G., Bursik, R. J., \& Cochran, J. K. (1991). “Render unto Caesar what is Caesar's": Religiosity and taxpayers' inclinations to cheat. The Sociological Quarterly, 32(2), 251-266

Gujarati, Damodar. (1995). Basic Econometrics. $3^{\text {rd }}$ edition ed. New York: Mc-Graw Hill, Inc.

Hanno, M. D., \& Violette, G. R. (1996). An Analysis of Moral and Social Compliance on Taxpayer Behaviour, Behavioural Research in Accounting, 8

Hasan, M. Iqbal. 1999. Pokok-pokok Materi Statistik 1 (Statistik Deskriptif). Jakarta: Bumi Aksara.

Hofmann, E., Hoelzl, E., \& Kirchler, E. (2008). Preconditions of voluntary tax compliance. Zeitschrift für Psychologie/Journal of Psychology, 216(4), 209-217.

Indra, Ismiawan. (2001). Memahami Reformasi Perpajakan. Jakarta: lekmedia Komputindo

Kiryanto. (1999). Pengaruh Penerapan Struktur Pengendalian Intern terhadap Kepatuhan Wajib Pajak Badan dalam Memenuhi Kewajiban Pajak Penghasilannya, Simpo-siom Nasional Akuntansi II. Universitas Brawijaya

Kiswara, E. (2009). Factors affect corporate taxpayers compliance level in Indonesia: An empirical review based-on planned behavior theory. Kertas kerja, Fakultas Ekonomi Universitas Diponegoro. Neuman, W. L

Konrad, K. A., \& Qari, S. (2012). The last refuge of a scoundrel? Patriotism and tax compliance. Economica, 79(315), 516-533

Leslie GR, Larson RF and Gorman BL (1973), Order and Change. New York: Oxford University Press

Maholtra, Naresh K. (2007). Marketing Research. New Jersey: Pearson Education Inc.

Martin AbrahamKerstin LorekFriedemann RichterMatthias WredeBreaking the norms: 2018 When is evading inheritance taxes socially acceptable?European Journal of Political EconomyVolume 52, March 2018, Pages 85-102

Massofa, (2008). Pengertian dan Faktor-Faktor yang Mempengaruhi Produktivitas Kerja, http://www.wordpress.com.

Mustikasari, E. (2007). Kajian Empiris tentang Kepatuhan Wajib Pajak Badan di Perusahaan Industri Pengolahan di Surabaya, Seminar Nasional Akuntansi X. Makasar

Nichita Ramona-Anca dan Bătrâncea Larissa-Margareta. (2012). The Implications of Tax Morale on Tax Compliance Behavior. Faculty of Economics and Business Administration. Faculty of Business 
Nurmantu, S. (2000). Dasar-dasar perpajakan. Jakarta: Ind-Hill-Co

Priyatno, Duwi SE. (2008). Paham Analisis Statistik Data Dengan SPSS. Yogyakarta: Mediakom

Resmi, S. (2007). Perpajakan Teori dan Kasus, Salemba Empat. Jakarta.

Riduwan dan Kuncoro, E.A. (2007). Cara Menggunakan dan Memaknai Analisis Jalur (Path Analysis). Bandung: Alfabeta

Riyanto, Triyono Hajid. (2012). Faktor-faktor yang Mempengaruhi Kepatuhan Wajib Pajak di KPP Jakarta Tahun 2009-2011. Tesis. Fakultas Ekonomi. Program Magister Perencanaan dan Kebijakan Publik. Universitas Indonesia.

Santoso, Singgih. (2000). Buku Latihan SPSS Statistik Parametrik. Jakarta: PT Elex Media Komputindo.

Santoso, Wahyu. (2008). Analisis Ketidakpatuhan Wajib Pajak Sebagai Dasar Peningkatan Kepatuhan Wajib Pajak. Jurnal Keuangan Publik. Vol.5 No.1, 85-137

Scholz, John, T., \& Lubell, M. (1998). Adaptive political attitude: Duty, trust and fear as monitors of tax policy. American Journal of Political Science, 42,398-417.

Sigala, M., Burgoyne, C. B., \& Webley, P. (1999). Tax communication and social influence: Evidence from a British sample. 241(June 1998).

Sniderman, P. M., Brody, R. A., \& Tetlock, P. E. (1993). Resoning and choice: Explorations in political psychology. Cambridge University Press

Sihombing, S.O. 2004. Hubungan Sikap dan Perilaku Memilih Satu Merek: Komparasi antara Theory of Planned Behavior dan Theory of Trying, Disertasi. Universitas Gajah Mada. Yogyakarta

Stack, S., \& Kposowa, A. (2006). The effect of religiosity on tax fraud acceptability: A cross-national analysis. Journal for the Scientific Study of Religion, 45, 325-351

Sugiyono. (2011). Metode Penelitian Kombinasi (Mixed Methods). Bandung: Alfabeta

Suharno, 2003, Pengelolan Pajak Bumi dan Bangunan dalam era Otonomi Daerah.

Supranto J dan Nandan Lima Krisna. (2012). Petunjuk Praktis Penelitian Ilmiah Untuk Menyusun Skripsi, Tesis dan Disertasi. Jakarta: Mitra Wacana Media

Susilowati, I. (2001). Evaluation of compliance behavior of fishers in the communities with different level of participation in Co-Management Processes (Cmps): A case study in Central Java fisheries, Indonesia. Hasil penelitian, ICLARM. Penang, Malaysia.

Talcott Parsons. (1960). The Struvture of Social Action. United States

Tarigan, R., (2005). Perencanaan Pembangunan Wilayah. Jakarta: Bumi Aksara

Tjahjono. (2006). Pengaruh Tingkat Kepuasan atas Pelayanan Perpajakan terhadap Tingkat Kepatuhan Wajib Pajak Orang Pribadi pada Kantor Wilayah Direktorat Jenderal Pajak Jawa Bagian Timur I, Tesis. Universitas Airlangga, Surabaya.

Torgler, Benno., Schaffnera,Markus and Macintyre, Alison. (2007). Tax Compliance, Tax Morale and Governance Quality. Working Paper No. 2007 - 17. CREMA Gellertstrasse 18 CH - 4052 Basel

Torgler, Benno, \& Scheneider, F. (2004). Attitudes towards paying taxes in Austria: An empirical analysis. Kertas kerja Yale Centre for International and Area Studies, Leither Program in International and Comparative Political Economy

Torgler \& Benno. (2002). Tax morale and institutions. WWZ Discussion Paper.

Tyler, T. R. (2000). Why do people cooperate in groups? Dalam V. V., Mark, M. Snyder, T. R. Tyler and A. Biel (Editor.). Cooperation in modern society: Promoting the welfare of communities, states, and organizations (hal. 65-82). London: Routledge.

Wenzel, M. (2004). An analysis of norm processes in tax compliance. Journal of Economic Psychology, 25(2), 213-228.

Massofa, (2008). Pengertian dan Faktor-Faktor yang Mempengaruhi Produktivitas Kerja, http://www.wordpress.com.

The World Fact Book https://www.cia.gov/library/publications/the-world-factbook/fields/2221.html 